\title{
O enigma de "Jabberwocky" na tradução de Augusto de Campos para o português brasileiro
}

The riddle of "Jabberwocky" in its translation into Brazilian Portuguese by Augusto de Campos

Doutoranda em Estudos de Literatura no Programa de Pós-Graduação em Letras da UFRGS. ProIntograda (URI) de Frederico Westphagion, Brasil. Mestre em Letras pela Universidade Presbiteriana Mackenzie, SP (2007), graduada em Letras (Português/Francês) pela PUCRS (1990) e em Filosofia pela U. Mackenzie (2006). Pesquisa as figuraçōes da imagem feminina na poesia e pinturas surrealistas.

E-mitis

iceargenta@gmail. com

Doutora em Literatura Anglo-americana pela Lingua Inglesa nos programas de graduarão pós-graduação do Instituto de Letras da UFRGS Mestre em Inglês e Literaturas Correspondentes pela UFSC (1982) e especialista em Literatura Vitoriana pela University of Leicester, Inglaterra (1989). Pesquisa a literatura dos periodos vitoriano e eduardiano. Coordena atualmente o projeto nas Literaturas de Lingua Inglesa (com apoio PROPESQ UFRGSCNPQ/FAPERGS). (D.) http:///orcid.org/0000-0001-6216-0761 E-mail: sandramaggio01@gmail.com
Marinice Argenta ${ }^{1}$ Universidade Regional Integrada, Instituto de Letras, Frederico Westphalen, RS, Brasil. Sandra Sirangelo Maggio² Universidade Federal do Rio Grande do Sul, Instituto de Letras, Programa de Pós-Graduação em Letras, Porto Alegre, RS, Brasil.

\section{RESUMO}

Este trabalho apresenta e localiza historicamente o conceito de nonsense a partir do poema "Jabberwocky", de Lewis Carroll, comentando certas escolhas de tradução da obra feitas por Augusto de Campos para a edição de 1980 da Editora Summus. "Jabberwocky", um clássico nonsense de língua inglesa, começou a ser composto por Carroll em 1855, tendo sido mais tarde integrado à obra Através do Espelho e o que Alice Encontrou Lá, em 1871. Tanto Carroll quanto Augusto de Campos tornam inteligível um texto que à primeira vista parece inacessível, através da criação de palavras novas e singulares (neologismos e portmanteaus). Os resultados de ambos os esforços compõem uma história compreensível, contada em versos. 0 entendimento do poema faz-se possível também em outras traduções para o português, porém optamos por comentar as escolhas feitas por Augusto de Campos, na tradução denominada "Jaguadarte", por configurarem a marca autoral de um dos mais renomados tradutores de poesia no Brasil. 0 trabalho representa, em suma, uma nota de apreciação sobre a genialidade da construção poética deste tradutor.

Palavras-chave: Tradução literária. Nonsense. Lewis Carroll. Jabberwocky. Augusto de Campos.

\section{ABSTRACT}

This work presents and historically locates the concept of nonsense through Lewis Carroll's poem "Jabberwocky". It also explores some choices made by Augusto de Campos in his translation of the poem into Brazilian Portuguese, made for the 1980 edition of Summus Publishing House. "Jabberwocky", a classic nonsense poem in the English language, started being written in 1855. In 1871, the complete text was incorporated into Through the Looking-Glass and What Alice Found There. Both Carroll and Campos manage to unfold an intelligible story told in verse out of a text that may seem impenetrable at first, due to its singular new words and meanings (neologisms and portmanteau words). The poem can be read and understood in other translations into Portuguese, but we concentrate on some choices made by Augusto de Campos in his translation - titled "Jaguadarte" - because they carry the authorial marks of one of the most respected translators of poetry in Brazil. This article represents a note of appreciation on the mastery of Augusto de Campos' poetical craftsmanship.

Keywords: Literary translation. Nonsense. Lewis Carroll. Jabberwocky. Augusto de Campos. 
"Às vezes até um poema aparentemente fácil é difícil de traduzir. Mas os mais difíceis tendem a ser considerados intraduziveis, e portanto ou não traduzidos ou traduzidos de qualquer maneira, com todas as facilidades que desfiguram o texto original. Traduzir com beleza e emoção os 'intraduzíveis' é sempre uma proeza. Mas há poemas que resistem à tradução, porque não se encontra na língua de chegada equivalências suficientes de 'forma e alma' para vertê-los ou convertê-los em peças igualmente belas e emotivamente eficazes. Já me aconteceu muitas vezes desejar traduzir um poema e não encontrar uma solução que me convencesse. Nesses casos, prefiro não traduzir. Acho que consegui em alguns casos, como em 'Jaguadarte', de Lewis Carroll, ou na 'Elegia', de Donne, uma boa equivalência. Poesia e tradução de poesia para mim é uma experiência da mesma natureza - um estado de poesia, que me envolve profundamente".

Augusto de Campos, Entrevista [1984].

$\mathrm{N}^{2}$

a epígrafe acima, Campos diz o que pensa sobre os desafios da tradução poética ${ }^{1}$. Quando um mestre desse porte se manifesta, nós pegamos o lápis e vamos anotando: (1) é melhor desistir de um poema do que traduzir e ficar descontente com o resultado; (2) quando se consegue transpor "forma e alma" de um poema difícil "com beleza e emoção", esse é um grande feito; (3) criar poesia ou traduzir poesia são experiências semelhantes, que pertencem ao que ele chama de "estado de poesia"; (4) de Campos se orgulha da tradução que fez do poema "Jabberwocky", no texto intitulado "Jaguadarte".

Apresentamos a seguir (Quadro 1) as "formas" das duas produções (pois a "alma" depende sempre do processo de leitura de cada indivíduo):

\footnotetext{
Augusto Luís Browne de Campos (1931) é um tradutor e poeta brasileiro. Fundou, com os poetas Haroldo de Campos (seu irmão) e Décio Pignatari, o Movimento Concretista Brasileiro. Ganhador dos prêmios Jabuti (1979 e 1993) e Pablo Neruda (2015), recenen 2016 acomenda da Ordem do Mér os poma tradutor da parte em prosa é Sebastião Uchoa Leite.
}

Quadro 1 - Cotejo dos dois poemas

\begin{tabular}{|l|l} 
JABBERWOCKY AGUADARTE & AGP
\end{tabular}

Lewis Carroll $\quad$ Augus

Roldavam e relviam nos gramilvos.

Estavam mimsicais as pintalouvas,

E os momirratos davam grilvos.

All mimsy were the borogoves,

And the mome raths outgrabe.

"Beware the Jabberwock, my son!

The jaws that bite, the claws that catch!

Beware the Jubjub bird, and shun

The frumious Bandersnatch!"

He took his vorpal sword in hand:

Long time the manxome foe he sought-

So rested he by the Tumtum tree

And stood awhile in thought.

And as in uffish thought he stood,

The Jabberwock, with eyes of flame,

Came whiffling through the tulgey wood,

And burbled as it came!

One, two! One, two! And through and through

The vorpal blade went snicker-snack!

He left it dead, and with its head

He went galumphing back.

"And hast thou slain the Jabberwock?

Come to my arms, my beamish boy!

O frabjous day! Callooh! Callay!”

He chortled in his joy.

'Twas brillig, and the slithy toves

Did gyre and gimble in the wabe;

All mimsy were the borogoves,

And the mome raths outgrabe.

"Foge do Jaguadarte, o que não morre! Garra que agarra, bocarra que urra!

Foge da ave Fefel, meu filho, e corre

Do frumioso Babassura!"

Ele arrancou sua espada vorpal

e foi atrás do inimigo do Homundo.

$\mathrm{Na}$ árvore Tamtam ele afinal

Parou, um dia, sonilundo.

E enquanto estava em sussustada sesta

Chegou o Jaguadarte, olho de fogo,

Sorrelfiflando através da floresta,

E borbulia um riso louco!

Um dois! Um, dois! Sua espada mavorta Vai-vem, vem-vai, para trás, para diante! Cabeça fere, corta e, fera morta,

Ei-lo que volta galunfante.

"Pois então tu mataste o Jaguadarte! Vem aos meus braços, homenino meu Oh dia fremular! Bravooh! Bravarte!"

Ele se ria jubileu.

Era briluz. As lesmolisas touvas Roldavam e relviam nos gramilvos. Estavam mimsicais as pintalouvas,

E os momirratos davam grilvos.

(CARROLL, 1987, p. 191-197) (CAMPOS, 1980, p. 146)

Fonte: Elaborado pelos autores. 


\section{1 “Jabberwocky" e os Alice Books}

Em uma tarde de verão de 1862, Lewis Carroll e outro professor de Oxford fizeram um passeio de barco com as três filhas do diretor do Christ College, onde lecionavam. Durante a viagem, Carroll inventou uma história cuja protagonista era a menor das três meninas, Alice Liddell. Ela ficou tão encantada com aquelas aventuras que solicitou que Carroll as escrevesse. Dois anos mais tarde, ele entregava para Alice, como presente de Natal, o manuscrito Alice's Adventures Under Ground, ilustrado por ele mesmo, que hoje consta como o item MS 46700 da coleção da British Library². No ano seguinte, a obra foi ampliada e publicada pela editora Macmillan sob o título definitivo Alice's Adventures in Wonderland. Como Carroll era um desenhista amador, ilustrações mais sofisticadas foram feitas pelo artista de ofício John Tenniel, sempre publicadas com a prévia concordância do autor. O livro foi muito bem recebido, fazendo de Carroll um escritor consagrado.

Seis anos depois, em 1871, veio o segundo livro de Alice, Through the Looking-Glass and What Alice Found There. É nessa obra que se encontra o nosso objeto de estudo, o poema "Jabberwocky", no primeiro capítulo, "Looking-Glass House". A obra principia de um modo curioso, com a ilustração de um tabuleiro de xadrez que contém alguns itens numerados que sinalizam os passos de uma partida ao longo da qual irá transcorrer toda a história e na qual cada personagem será uma das peças do jogo, inclusive a própria Alice.

Depois temos um poema, anunciando que o livro consiste em uma ficção de fantasia que está sendo ofertada como um presente para alguém. Abre-se então o primeiro capítulo, no qual Alice atravessa para o outro

\footnotetext{
2 Esse manuscrito, que revela também o apuro dos desenhos feitos por Carroll, pode ser visualizado em sua íntegra online. Disponível em: https://www.bl.uk/collection-items/alices-adventures-under Acesso em: 11 fev 2018 .
}

lado de um espelho, chegando a uma sala idêntica àquela em que estava, porém invertida, isto é, espelhada. A partir daí desencadeiam-se várias travessias absurdas por um mundo de aventuras muito similar ao da obra Alice's Adventures in Wonderland. Nesse lugar as peças de xadrez agem como seres humanos; e os animais, insetos e flores falam. Há uma lógica entre o desenrolar do capítulo e a sequência de passos determinados pelo jogo de xadrez, que se mantém até o final, quando Alice - que era um peão - vence e se torna a rainha.

Figura 1 - Atravessando o espelho (John Tenniel, 1871)
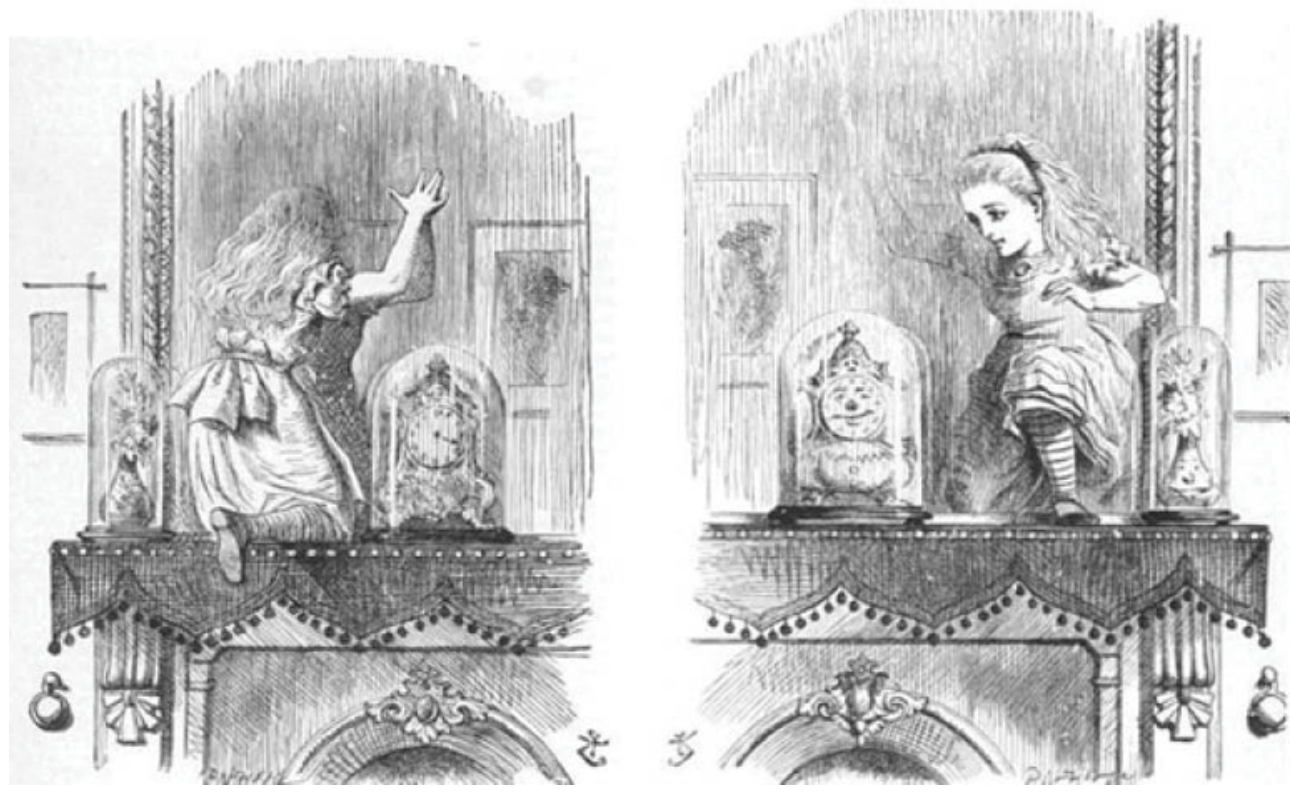

Fonte: Captura de imagem de Wikimedia ${ }^{3}$

Disponível em: https://upload.wikimedia.org/wikipedia/commons/9/96/Aliceroom3.jpg. Acesso em: 23 set. 2018. 
O primeiro capítulo inicia com Alice acomodada em uma grande poltrona na sala de sua casa, observando uma gata e seus filhotes. Após colocar um dos filhotes junto a si na poltrona, a gatinha Kitty, Alice convida o filhote para jogarem xadrez em um tabuleiro disposto na sala. Alice conversa consigo mesma e com a gatinha alternadamente, mas solicita que Kitty apenas a ouça, sem replicar, para que ela possa apresentar todas as suas ideias. Enquanto prossegue exprimindo seus pensamentos, convida-a, então, para atravessarem para a "Casa do Espelho".

Das cinquenta e duas ilustrações feitas por Tenniel para a primeira edição de Through the Looking Glass, apresentamos aqui as figuras três e quatro do primeiro capítulo, que mostram o movimento de Alice quando passa de um ambiente para o outro.

Já no outro lado do espelho, Alice ouve o Rei e a Rainha conversando entre si no tabuleiro de xadrez, e percebe que, para eles, ela não existe. Como o Rei está tendo dificuldades para subir à mesa do tabuleiro, Alice o ajuda e lhe dá uma espanada, para limpá-lo das cinzas da lareira. Como não pode vê-la, ele se surpreende. Atônito, sem saber como explicar o episódio, ele decide registrá-lo em um bloco de anotações.

Enquanto o Rei faz suas anotações, Alice percebe que há um livro sobre a mesa e começa a folheá-lo. Depara-se com um texto bizarro, que não consegue ler. A princípio pensa que se trata de um outro idioma, mas logo se dá conta de que o texto está espelhado:

\section{YKCOWREBBAJ}

sevot yhtils eht dna ,gillirb sawT"

ebaw eht ni elbmig dna eryg diD

,sevogorob eht erew ysmim llA

.ebargtuo shtar emom eht dnA (CARROLL, 1987, p. 191).

Então, lembrando-se de onde está, segura o livro diante do espelho e começa a leitura:
Quadro 2 - Primeira estrofe dos dois poemas

\begin{tabular}{|l|l|}
\hline 'Twas brillig, and the slithy toves & Era briluz. As lesmolisas touvas \\
Did gyre and gimble in the wabe; & Roldavam e relviam nos gramilvos. \\
All mimsy were the borogoves, & Estavam mimsicais as pintalouvas, \\
And the mome raths outgrabe. & E os momirratos davam grilvos. \\
(CARROLL, 1987, p. 191). & (CAMPOS, 1980, p. 146). \\
\hline
\end{tabular}

Fonte: Elaborado pelos autores.

\section{Sobre "Jabberwocky" e seu autor}

Martin Gardner, responsável pela edição comentada The Annotated Alice, nos informa que Carroll (1832-1898) já havia começado a compor "Jabberwocky" aos vinte e três anos, em 1855, quando divulgou a primeira estrofe do poema em uma edição dos periódicos Mischmasch, que ele mesmo compunha e ilustrava manualmente para um público restrito formado por familiares (GARDNER, 2002, p. 145) 4 . Essa prática não era incomum entre jovens intelectuais daquela época. As publicações caseiras de Carroll evocam a dupla Jane e Cassandra Austen apresentando sua História da Inglaterra (escrita por Jane e ilustrada por Cassandra) para os amigos, ou os livros de cinco centímetros escritos e encadernados pelos quatro irmãos Brontë (Anne, Branwell, Charlotte e Emily), com as narrativas do reino de Angria e os poemas de Gondal.

O título original desses quatro primeiros versos do que depois iria se tornar o "Jabberwocky" era Stanza of Anglo-Saxon Poetry. Carroll dispôs o texto imitando os tipos gráficos da escrita rúnica (que não iremos reproduzir aqui), utilizando também a forma arcaica 'ye' ao invés da grafia usual 'the'

${ }^{4}$ The Annotated Alice, composto originalmente por Martin Gardner para a editora Norton na década de 1960, é até hoje uma das melhores fontes de informação sobre os Alice Books. Salvo quando expressamente referenciado de outra forma, as informações factuais sobre o autor e o poema apresentadas neste artigo se apoiam nas notas de Gardner. 
para o artigo definido. A sonoridade das palavras evoca os poemas do inglês antigo, onde o que mais importa é o jogo de sons na parte interna do verso. $\mathrm{O}$ fato de as palavras "bryllig", "slythy" e "toves" não significarem nada também contribui para tornar o texto misterioso e desafiador. Esses cuidados com a forma gráfica - a escrita rúnica, a sonoridade, os jogos de significado indicam como a atenção de Carroll se dirigia para vários pontos da escrita ao mesmo tempo e mostram o artista multifacetado que ele é. Além de escritor, foi professor de matemática na Universidade de Oxford, diácono da Igreja Anglicana, pioneiro na arte da fotografia, desenhista, inventor de jogos de lógica e de palavras cruzadas. Seu nome de batismo era Charles Lutwidge Dodgson, mas em suas funções religiosas ele gostava de usar a versão latina e invertida de seus dois primeiros nomes: Ludovicus Carolus. Como escritor, criou o famoso pseudônimo Lewis Carroll retraduzindo os prenomes do latim para o inglês.

A técnica utilizada em "Jabberwocky" consiste em juntar pedaços de palavras independentes, criando assim um terceiro significado através de um amálgama que ficou conhecido como 'palavra-valise' (portmanteau word). James Joyce segue essa fórmula em seus textos, em especial em Finnegans Wake. No artigo "Allusions on Lewis Carroll in James Joyce's Finnegans Wake", Tamar Gelashvili aponta algumas dessas ocorrências. Joyce não apenas cria jogos de sentido, palavras e frases lidas de trás para a frente e palavras-valise - como fazia Carroll - como também faz referências diretas ao escritor inglês e sua obra. No trecho "All old Dadgerson's dodges one conning one's copying and that's what wonderland's wanderlad'll flaunt to the fair" (JOYCE, 2010, p. 347), identificamos menções ao sobrenome Dodgson e ao País das Maravilhas (Wonderland). Gelashvili aponta uma referência a "Jabberwocky": "Tis jest jibberweek's joke" (JOYCE, 2010, p.565) e três referências ao periódico de Carroll Mischmasch (que em alemão significa 'bagunça' ou 'confusão'): “mitsch for matsch” (JOYCE, 2010, p. 366); "mishmash mastufractured on europe you can read off the tail of his", (JOYCE, 2010, p. 466); e "(mschlmsch!) with nurse Madge, my linking class girl” (JOYCE, 2010, p. 459) 5 .

Por haver inventado várias técnicas de vanguarda, Carroll se ergue como um dos precursores de importantes movimentos artísticos que surgiriam décadas adiante, como o Modernismo e o Surrealismo. Não é à toa que James Joyce presta seu tributo a ele, ou que Salvador Dalí, em 1969, cria doze heliogravuras em sua homenagem para uma edição limitada de Alice's Adventures in Wonderland da editora Random House ${ }^{6}$. Carroll escreveu mais de oitenta poemas, vários dos quais integram os Alice Books. Dentre eles, "Jabberwocky" e "The Hunting of the Snark" são considerados dois clássicos do gênero nonsense.

A palavra nonsense vem do inglês e caracteriza algo que não tem lógica, não faz sentido, o que por vezes pode ser muito engraçado. 0 nonsense é uma marca do humor britânico, consistindo em uma sequência sutil de elementos aparentemente desconcatenados que provocam um efeito cômico justamente por não terem pé nem cabeça. As parlendas inglesas, ou nursery rhymes, têm como características principais o ritmo, a sonoridade, e o nonsense. Dois escritores ingleses do século XIX considerados mestres do nonsense são Lewis Carroll e Edward Lear. No século XX esse estilo é desenvolvido nos movimentos Surrealista e Dadaísta e mais tarde no Teatro do Absurdo.

\section{3 o “Jabberwocky”, de Lewis Carroll}

Quando termina a leitura do poema invertido, Alice tem impressões contraditórias a respeito:

5 Cf. GELASHVILI, 2016, p. 2.

6 Ilustrações podem ser consultadas online. Disponível em: https://www.brainpickings.org/2016/ 09/02/salvador-dali-alices-adventures-in-wonderland. Acesso em: 11 fev. 2018. 
- Parece muito bonito - disse quando terminou, - mas é um pouco difícil de entender! - (Como você vê, não queria confessar nem para si mesma que não entendera patavina.) - Seja como for, parece encher minha cabeça de ideias...só que não sei exatamente que ideias são. De todo modo, alguém matou alguma coisa: isto está claro, pelo menos... (CARROLL, 2002, p. 145).

Essa citação revela uma divergência entre o entendimento de Alice e o do narrador da passagem. A interferência entre parênteses do narrador tem o intuito cômico de escarnecer da menina, enfatizando que ela não entendeu "patavina" do que havia lido. Mas o itálico em "um pouco" revela que para ela o poema, apesar de cifrado, não é tão difícil assim de compreender. No final, ela se congratula por perceber que 'alguém matou alguma coisa'. A discrepância entre o narrador e a personagem indica que Alice está se saindo bem como leitora nessa realidade espelhada, onde a intuição pode ser mais útil do que o raciocínio lógico. Alice realiza movimentos de um leitor experiente. Ela pode não dominar o significado de certos substantivos, mas conhece os marcadores de categorias gramaticais, a disposição dos elementos sintáticos em uma frase e as impressões que as partes das palavras-valise evocam. Na tradução de Campos os segmentos que formam a palavra Jaguadarte remetem (entre outras possibilidades) aos termos jaguar (ou onça, o maior felino da fauna brasileira) e arte. Assim, aos poucos, Alice (e os demais leitores) vão encontrando pontos de apoio através dos quais conseguem imaginar o que está acontecendo na história.

Outros tradutores de "Jabberwocky" para o português do Brasil também encontraram suas soluções, todas muito interessantes, como indica esta breve amostragem de títulos para o poema: "Algaravia", por Oliveira Ribeiro Netto (CARROLL, 1984); "Blablassauro", por Ricardo Gouveia (CARROLL, 1997); "Bestialógico", por Eugênio Amado (CARROLL, 1999); "Pargarávio", por Maria Luiza X. de A. Borges (CARROLL, 2002); ou "O Tagarelão", por William Lagos (CARROLL, 2004) ${ }^{7}$.

A sensação de estranhamento de Alice diante do texto impresso no livro do espelho ocorre em duas etapas. Primeiro, quando vê o poema sobre o papel e imagina que se trate de um desses idiomas diferentes. Esse choque também ocorre com o leitor das edições do livro, que apresentam a primeira estrofe espelhada e só depois mostram o poema inteiro em grafia normal, quando Alice o coloca diante do espelho. O segundo desafio enfrentado por Alice é o de decodificar os significados cifrados, algo que é mais fácil de ser feito por uma criança que por um adulto, como o narrador que zomba dela. Alice sente-se instigada, anima-se com o texto que a enche de ideias, como ocorre com pessoas quando se deparam com uma obra de arte que, mesmo sendo incompreensível a princípio, é inspiradora.

Já nós, leitores, estamos um pouco com Alice, dentro da Casa do Espelho, e um pouco do lado de fora, sentados na poltrona, segurando o livro que lemos. E esse livro, quando apresenta o poema, geralmente traz a ilustração de Tenniel, ou uma releitura dela. Ainda que o texto seja uma bagunça semântica, a imagem está lá para nos ajudar, apresentando informações visuais que Alice não teve enquanto descobria que existe alguém que mata alguma coisa. O "alguém" é a criança que está de costas, segurando uma espada - que deve ser mágica, considerando a desproporção de força entre os dois oponentes. 0 monstro é grande e amedrontador, tem asas de dragão, cabeça de cobra, mãos de grifo e garras de réptil.

Essa imagem fazia parte do projeto original, concebido a partir de conversas entre Tenniel e Carroll. Ambos sabiam que os leitores enxergariam e analisariam a ilustração quando estivessem lendo o texto. Todos os leitores

7 Sugerimos aos interessados em averiguar essas e outras traduç̃̃es de "Jabberwocky" o sítio de interne Alucinagens. Disponível em: http://alicenagens.blogspotcom/2009/09/jabberwocky-in-portuguese. html. Acesso em: 16 jun. 2018. 
veriam a mesma criatura, que lembra os monstros das sagas anglo-saxãs que inspiraram a primeira estrofe criada pelo jovem Carroll quase vinte anos antes da publicação do livro.

Figura 2 - "Jabberwocky" (John Tenniel, 1871)

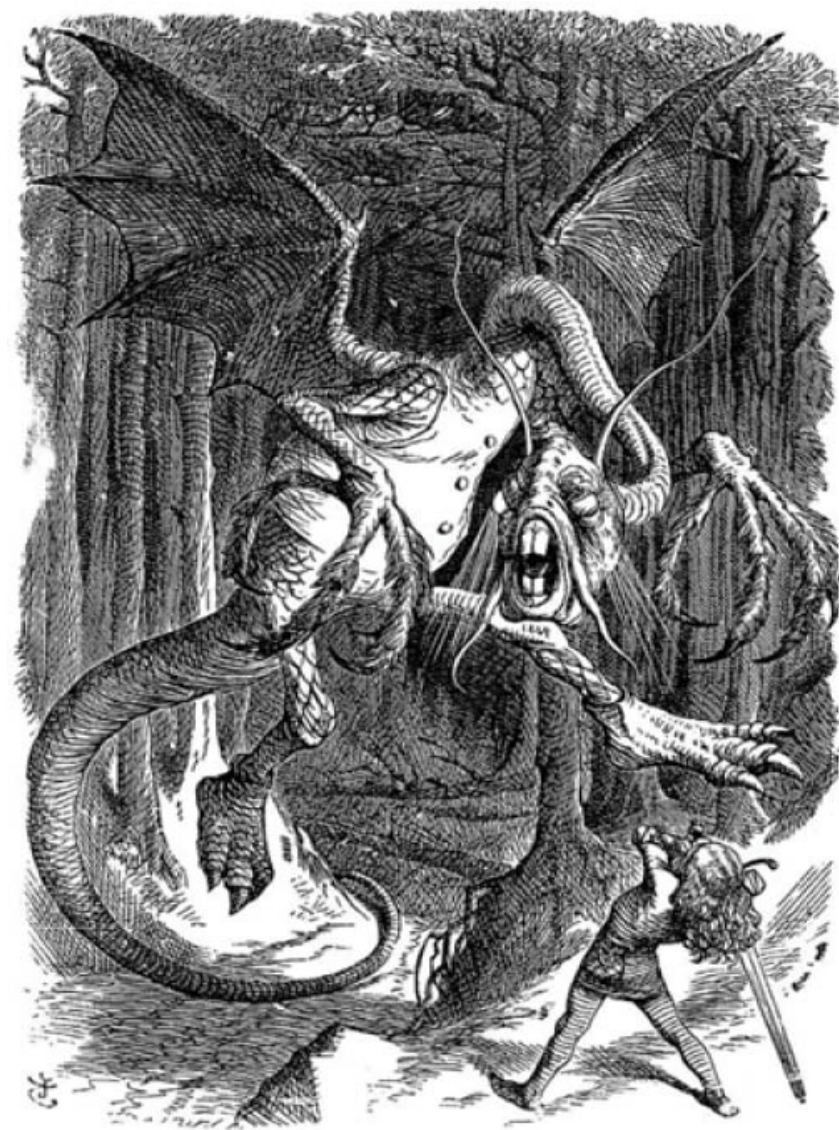

Fonte: Captura de imagem de Wikimedia ${ }^{8}$.

${ }_{8}^{8}$ Disponível em: https://en.wikipedia.org/wiki/File:Jabberwocky.jpg. Acesso em: 23 set. 2018.
Mesmo que Alice não tenha contado com a ajuda da ilustração de Tenniel, ela é uma leitora de língua inglesa, acostumada - mesmo que de maneira inconsciente - com as narrativas de aventuras nórdicas, nas quais um jovem herói jovem precisa enfrentar um monstro com força sobrehumana. Ela não tem dificuldade em identificar o herói, o antagonista e a voz que se dirige ao protagonista utilizando a expressão "meu filho". Como essa voz no final está cheia de alegria e orgulho, Alice conclui que tudo termina bem.

\section{0 "Jaguadarte", de Augusto de Campos}

A partir do título do livro, Through the Looking Glass, já se depreende o sentido metafórico inerente à imagem do espelho. Ou seja, sabemos que, para uma maior compreensão do texto, é necessário perscrutá-lo, desvendá-lo das mais variadas formas, "virá-lo do avesso" - expressão popular que significa analisar em profundidade, realizar um estudo meticuloso sobre algo. Partindo dessa premissa, passamos a esmiuçar o poema de Carroll através das escolhas de Campos.

O título "Jabberwocky" é uma palavra-valise que une o verbo "to jabber", que significa dizer coisas incoerentes, e "wacky" um tipo de comportamento que indica que alguém está maluco, perdeu a sanidade mental. No original, o título do poema é "Jabberwocky", enquanto que o nome do monstro é "Jabberwock", sem o ípsilon, que em inglês adiciona a ideia de "A história do", ou "A lenda do". Essa diferença, que se perde na tradução de Campos, onde o título do poema é o nome do antagonista, uma criatura de nome que faz lembrar a palavra "jaguar", ou onça-pintada, o terceiro maior felino do mundo e o maior das Américas. Assim, Campos acrescenta cor local a sua tradução, que começa: 
Era briluz. As lesmolisas touvas

Roldavam e relviam nos gramilvos.

Estavam mimsicais as pintalouvas,

E os momirratos davam grilvos

(CAMPOS, 1980, p. 146).

A primeira frase, "Era briluz", começa com um verbo que costuma introduzir situações (como em "Era verão", ou "Era uma vez"). A palavravalise que segue, evoca ideias como, por exemplo, "abril", "brilho", "luz", nos levando a imaginar um cenário tranquilo, como o de uma manhã de dia claro. Assim, desenvolvendo uma possível interpretação, temos um bonito dia de sol primaveril na Inglaterra, quando criaturas atarefadas (lesmolisas, pintalouvas, mormirratos) praticavam as ações de rotina (roldavam, apresentavam-se mimsicais e emitiam grilvos). Os segmentos "relv-" e "gram-" indicam que se movimentavam na relva ou na grama.

Na segunda frase do primeiro verso, surge o substantivo feminino plural "lesmolisas", e visualizamos o molusco terrestre "lesma", que tem uma pele "lisa". Percebemos que a repetição do som /l/ (já presente em "briluz") e das consoantes (também ecoando "briluz") contribui para o andamento sonoro do poema, por meio de aliterações. As estratégias de versificação de Carroll e de Campos mostram-se similares no tratamento sonoro do poema. Como ocorre nas poesias antigas anglo-saxãs, as aliterações são mais importantes que as rimas. Alguns exemplos, em "Jaguadarte”, são "Garra que agarra, bocarra” (verso 6); "Estava em sussustada sesta" (verso 13); e "Cabeça fere, corta e, fera morta” (verso 19).

Os segmentos finais nas conjugações dos verbos "roldavam" e "relviam" indicam o tempo passado em que ocorriam as ações sobre os "gramilvos", com as criaturas se movendo de diferentes formas pelo relvado. A seguir encontramos as "pintalouvas", que lembram os pintassilgos ou os louva- deuses, que talvez cantem, pois a palavra "mimsicais" traz a ideia de música. Começamos a nos acostumar com a brincadeira. Quando nos deparamos com os "momirratos" dando "grilvos", imaginamos algum roedor pequeno produzindo alguma espécie de som.

Apesar de o narrador de Through the Looking Glass achar que Alice não está entendendo "patavina", tanto ela como qualquer leitor com um pouco de paciência conseguem tatear significados, percebendo que não há necessidade de dominar o significado de cada palavra. Uma vez disparada a associação, surge um tipo de compreensão arquetípica, na medida em que nos é oferecida uma aglutinação de ideias que propicia o discernimento sucessivo e espontâneo dos elementos apresentados.

A primeira estrofe transcorre em perfeita harmonia, mas essa paz é subitamente quebrada ao abrir da segunda estrofe, que apresenta uma fala em discurso direto:

"Foge do Jaguadarte, o que não morre!

Garra que agarra, bocarra que urra!

Foge da ave Fefel, meu filho, e corre

Do frumioso Babassura!" (CAMPOS, 1980, p. 146).

As aspas marcam a intervenção de alguém que alerta àquele a quem chama de filho sobre os perigos do Jaguadarte, da ave Fefel e do frumioso Babassura. Deduzimos, assim, que há perigos escondidos naquele cenário aparentemente tão calmo. O primeiro a ser mencionado é o perigoso Jaguadarte, uma fera furiosa e feroz, que tem asas, garras, um bramido potente e que é invencível, posto que não morre, segundo o advertente. Essa voz que fala pode ser lida como um pai, uma mãe, ou qualquer tipo de guardião que alerta o jovem protagonista sobre o animal atroz. $O$ contraste entre a tranquilidade da primeira estrofe e o grito de alerta da segunda provoca a movimentação dos acontecimentos. 
Ele arrancou sua espada vorpal

e foi atrás do inimigo do Homundo.

$\mathrm{Na}$ árvore Tamtam ele afinal

Parou, um dia, sonilundo. (CAMPOS, 1980, p. 146).

$\mathrm{Na}$ terceira estrofe, a personagem que foi avisada revela traços de intrepidez e valentia, pois ao invés de fugir, saca de sua espada e ruma de encontro ao perigoso animal, que é o inimigo de todos, pois a palavra "Homundo" remete ao "mundo todo", a "todos os homens". O menino parece ter caminhado muito, a ponto de ficar exausto, tendo finalmente que parar para descansar sob a árvore "Tamtam", pois encontra-se "sonilundo". Ao adormecer, ele baixa a guarda contra o perigoso Jaguadarte.

E enquanto estava em sussustada sesta,

Chegou o Jaguadarte, olho de fogo,

Sorrelfiflando através da floresta

E borbulia um riso louco! (CAMPOS, 1980, p. 146).

Como sempre, o inimigo surge quando menos se espera. Vem o Jaguadarte, com o "olho de fogo", "sorrelfiflando" - com a respiração de um animal feroz se infiltrando sorrateiramente - e um "riso louco". Temos aqui, finalmente, a determinação do ambiente: uma floresta.

Tais fatos, como descobriremos a seguir, não atemorizam o nosso herói:

Um dois! Um, dois! Sua espada mavorta

Vai-vem, vem-vai, para trás, para diante!

Cabeça fere, corta e, fera morta,

Ei-lo que volta galunfante (CAMPOS, 1980, p. 146)

Contra todas as probabilidades, como é próprio das sagas heroicas, ele enfrenta a fera com sua espada, desferindo com energia vários golpes - "vai-vem, vem-vai" - subjugando-a e a levando à morte. Após concluir a façanha, retorna "galunfante", um amálgama que pode remeter (entre outras variantes) a "galopando", "galante", ou "triunfante", satisfeito e exultante com seu feito, para honrar a família e receber os elogios a que faz jus.

"Pois então tu mataste o Jaguadarte!

Vem aos meus braços, homenino meu!

Oh dia fremular! Bravooh! Bravarte!"

Ele se ria jubileu (CAMPOS, 1980, p. 146)

Está concluído o rito de passagem, e o menino se torna um herói vitorioso. Nessa estrofe, da mesma forma que na segunda, abrem-se aspas para a voz da família se pronunciar, cumprimentando o rapaz por haver destruído o Jaguadarte. Fechadas as aspas do discurso direto, o "ele" que ri "jubileu" é provavelmente o menino, contente e jubiloso com o desfecho da árdua empreitada.

Era briluz. As lesmolisas touvas

Roldavam e relviam nos gramilvos.

Estavam mimsicais as pintalouvas,

E os momirratos davam grilvos (CAMPOS, 1980, p. 146).

A última estrofe do poema repete a primeira, indicando que a ordem retornou àquele pequeno mundo. As lesmolisas, as pintalouvas e os momirratos seguem com sua rotina agradável em outra manhã ensolarada. Essa repetição dá ao poema uma forma circular, como a do ouroboros, a imagem arquetípica de uma serpente (ou dragão) que abocanha a ponta da própria cauda. Descortina-se a estrutura de uma narrativa épica que tem versos com dimensão espacial, temporalidade, ação e personagens, evidenciando a trajetória de um herói que realiza seus feitos e caminha, ou cavalga, ou galopa vitorioso, cônscio de sua responsabilidade para com o bem de todos. 


\section{Considerações finais}

O título deste artigo faz referência ao enigma que "Jabberwocky" (assim como os demais textos do gênero nonsense) representa. No nosso entender, "Jabberwocky" é como um quebra-cabeça que cada leitor monta a sua maneira, de modo que as imagens que se formam são diferentes em cada finalização. Quando um texto nonsense é traduzido para outro idioma, as análises tendem a investigar de que maneiras os sentidos possíveis do poema original atingem, espelhados, os leitores do novo contexto. Esse rico terreno de cotejo permanece aberto para ser explorado em cada uma das traduções de "Jabberwocky" para o português do Brasil, de modo que estes breves comentários sobre algumas das escolhas feitas pelo mestre Augusto de Campos têm por objetivo convidar outros pesquisadores a empreenderem esforços para compreender tanto os enigmas propostos no poema original quanto as estratégias utilizadas por tradutores para transportá-los para outras culturas. O maior desafio recai sobre os aspectos poéticos do original, de forma que mantenham efeitos semelhantes na língua-alvo. Cada tradutor faz as suas escolhas com respeito ao tratamento da rima, do ritmo, da sonoridade, da métrica. No caso de "Jaguadarte", as soluções de Campos conseguem criar um texto cheio de aliterações e assonâncias, em uma métrica que se alinha a do original. Tanto no original quanto nessa tradução, apesar do conjunto de palavras à primeira vista incompreensíveis, que propõem o enigma a ser decifrado, temos uma mescla de elementos "estruturados nos moldes tradicionais ou desestruturados em obras mais revolucionárias" (SOARES, 1999, p. 77).

Segundo André Jolles, em Formas Simples, "não apreendemos a poesia em sua fixação artística definitiva, mas onde ela ganha raízes, isto é, na linguagem" (JOLLES, 1976, p. 18). Destarte, ao término desta leitura de "Jaguadarte", sentimo-nos, como Alice, cheios de ideias, satisfeitos porque exploramos o texto, criando assimilações modeladas por padrões já existentes na fala ou então simplesmente ajustando, deduzindo ou coadunando os verbetes aos versos e às estrofes. Assim, podemos nos aproximar daquele "estado de poesia" que nos envolve profundamente, como aponta Campos na epígrafe introdutória deste trabalho.

\section{Referências}

CAMPOS, Augusto de. Entrevista com Augusto de Campos no Joycentenário. Depoimento. 1984. Ilha do Desterro: a journal of language and literature, Florianópolis, v. 5, n. 12 , p. $25-35,1984$.

CAMPOS, Augusto de. Jaguadarte. In: CARROLL, Lewis. Aventuras de Alice: Alice no país das maravilhas; através do espelho e o que Alice encontrou lá. Tradução de Sebastião Uchoa Leite (prosa) e Augusto de Campos (poemas). São Paulo: Summus, 1980. p. 146. https://doi.org/10.19146/pibic-2016-50619

CARROLL, Lewis. Alice's adventures under ground. [1862-64]. 2015. Manuscrito disponível na British Library. Disponível em: https://www.bl.uk/collection-items/ alices-adventures-under-ground-the-original-manuscript-version-of-alices-adventures-inwonderland. Acesso em: 06 fev. 2018. https://doi.org/10.1017/cbo9781139568555.009

CARROLL, Lewis. Alice: edição comentada de Alice no país das maravilhas e Através do espelho. Tradução de Maria Luiz X. de A. Borges. Rio: Jorge Zahar, 2002.

CARROLL, Lewis. Alice no fundo do espelho. Tradução e adaptação de Oliveira Ribeiro Netto. São Paulo: Cia. Editora Nacional, 1984.

CARROLL, Lewis. Alice no país do espelho. Tradução de William Lagos. Porto Alegre: L\&PM, 2004.

CARROLL, Lewis. Aventuras de Alice: Alice no país das maravilhas; através do espelho e o que Alice encontrou lá. Tradução de Sebastião Uchoa Leite (prosa) e Augusto de Campos (poemas). São Paulo: Summus, 1980. https://doi.org/10.19146/ pibic-2016-50619 
CARROLL, Lewis. Do outro lado do espelho. Edição condensada. Tradução de Ricardo Gouveia. São Paulo: Martins Fontes, 1997.

CARROLL, Lewis. Lewis Carroll: obras escolhidas. Tradução de Eugênio Amado. Belo Horizonte: Itatiaia, 1999. 2v.

CARROLL, Lewis. Through the looking-glass, and what Alice found there.

In: CARROLL, Lewis. The annotated Alice. Introdução e notas por Martin Gardner.

Harmondsworth: Penguin, 1987.

GARDNER, Martin. Comentário sobre "Jabberwocky". In: CARROLL, Lewis.

Alice: edição comentada de Alice no país das maravilhas e Através do espelho.

Tradução de Maria Luiz X. de A. Borges. Rio de Janeiro: Jorge Zahar, 2002.

https://doi.org/10.11606/issn.2316-9826.literartes.2014.89210

GARDNER, Martin (ed.). The annotated Alice: the definitive edition. 4th. ed. New York: W. W. Norton, 2000.

GELASHVILI, Tamar. Allusions on Lewis Carroll in James Joyce's Finnegans wake. 2016. International Journal of Research in Humanities, Arts and Literature, [S.l.],

v. 4, n. 5, may 2016, p. 47-54. Disponível em: https://pt.scribd.com/doc/316076944/ ALLUSIONS-ON-LEWIS-CARROLL-IN-JAMES-JOYCE-S-FINNEGANS-WAKE. Acesso em: 06 fev. 2018. https://doi.org/10.2307/j.ctv47w940.7

JOLLES, André. Formas simples. São Paulo: Cultrix, 1976.

JOYCE, James. Finnegans wake [1939]. [S. l.], 2010. Edição online. Disponível em: http://www.finwake.com/. Acesso em: 06 fev. 2018.

SOARES, Angélica. Gêneros literários. São Paulo: Ática, 1999.

STEWART, Jessica. Salvador Dalí's Rarely Seen Alice in Wonderland illustrations are finally reissued. Art Achives. My Modern MET. [S.l.], 31 Jul. 2017. Disponível em: https://mymodernmet.com/salvador-dali-alice-in-wonderland. Acesso em: 07 fev. 2018.
TRADUÇÕES de Jabberwocky em português. Blog da Psicologia da Educação. [S.l.], 2010. Disponível em: https://www.ufrgs.br/psicoeduc/variados/traduzir-lewiscarroll/. Acesso em: 22 maio 2017.

Recebido em: 23/9/2018.

Aprovado em: $14 / 1 / 2019$

Publicado em: 20/6/2019. 